IOS Press

\title{
Fighting trafficking of falsified and substandard medicinal products in Russia
}

\author{
N.F. Fayzrakhmanov* \\ Investigation Department of the Ministry of Internal Affairs of the Republic of Mari El, Yoshkar-Ola, \\ Russia
}

*Corresponding author. E-mail: nfaizer@yandex.ru

BACKGROUND: The trafficking of falsified and substandard medicinal products is a global socioeconomic problem, which poses a serious threat to economy and health of populations of most countries, including the Russian Federation.

OBJECTIVE: To identify the main achievements and challenges in the fight against trafficking of falsified and substandard medicinal products in the Russian Federation, to formulate possible solutions to these problems.

METHODS: The study of criminal cases and statistical information about the level of crime in the Russian Federation; legal analysis of regulatory legal acts in the sphere of criminal law and turnover of medicinal products; review of scientific and practical publications.

RESULTS: The problem of trafficking of falsified and substandard medicinal products in the Russian Federation was publicly discussed in the late 1990s - early 2000-ies, first in the media and special editions, later this phenomenon was the subject of extensive discussions at international conferences, in public authorities and public circles. However, the most significant results in tackling this problem were achieved only in the last 5 years.

Thus, in 2010, the Russian Federation first joined the annual international police operation under the code name Pangaea, held since 2008 on the initiative of Interpol and the Medicines and Healthcare products Regulatory Agency of the World Health Organization (MHRA WHO). From year to year, the special operation Pangea unites the efforts of many countries from different continents and aims to eliminate transnational criminal groups operating through a global network the Internet. In 2010, as a result of large-scale international inspections 1200 Internet sites were revealed, through which the fake medicines were spread and 10,000 boxes of medicines were seized, making more than a million falsified tablets in the amount of 2.6 million USA dollars. In 2011, in a special operation Pangea IV was attended by 165 different organizations from 81 countries, including 72 customs, 30 regulators, 26 police and representatives of Interpol from 37 countries. Closed 13495 illegal websites, seized about 8,000 packages of fake medicines, containing about 2.5 million doses. In 2015 , the special operation Pangea VIII was held on the territory of 115 member States of Interpol. In the Russian Federation this operation was carried out jointly by the Ministry of internal Affairs, Federal customs service, the Federal Service on Surveillance in Healthcare of Russian Federation, the Federal Drug Control Service of the Russian Federation and their regional subdivisions. As a result of this operation 34 criminal cases were initiated in our country in connection with hard drugs, falsified and substandard medicinal products and biologically active additives under the guise of high-performance drugs. Special attention during the 
operation was given to uncontrolled Internet sale of medicinal products and biologically active additives at a price, which was significantly higher than the actual costs, under the guise of highly effective means of treatment for various diseases. In General, in the Russian Federation 448 administrative offences were identified, which resulted in withdrawal of more than 268 thousand units of medicines from illegal circulation, worth over 9 million rubles; 40 thousand falsified and substandard preparations Contex and Durex for personal contraception were withdrawn. The mobile laboratory has conducted screening program of quality in respect of 294 samples of medicines. It identified 20 parties of dubious authenticity. A message about 264 Internet sites which sell medicines in violation of applicable Russian legislation was sent to the coordinating headquarters of the General Secretariat of Interpol. An official statement with Internet service providers on cessation of activities at these sites was issued [1].

On 26-28 October 2011, Moscow hosted an international high-level conference on counterfeiting of medicinal products, which was attended by more than 750 professionals in the field of law and pharmacy from different countries, including USA, China, countries of the European Council and the Commonwealth of Independent States. At the end of the conference the Convention on the counterfeiting of medicinal products and similar crimes involving threats to public health, was signed, which was called Medicrime [2]. The Convention was signed by representatives of Austria, Germany, Israel, Iceland, Italy, Cyprus, Portugal, Russian Federation, Finland, France, Ukraine, Switzerland. The Medicrime Convention is the first legal agreement in the field of criminal law aimed at criminalizing the trafficking of falsified and substandard medicinal products, as well as aimed at providing legal support for the investigation of these crimes at the international level. The positive side of the Convention of the Council of Europe Medicrime is that it is open for signature not only by member States of the Council of Europe and the European Union, but also by States that are not members of the Council of Europe, but participated in the elaboration of a Convention or have observer status with the Council of Europe. In addition, the Convention is open for signature by any other state at the invitation of the Committee of Ministers of the Council of Europe. The Convention introduces the responsibility for the production, storage and distribution of falsified medicinal products, active substances, excipients, components, materials and supplies; the use of falsified documents related to the trafficking of medicinal products (Articles 5,6,7). This legal act regulates the cooperation between the health authorities, customs, police and other competent authorities at international and national level (Articles 17, 21, 22).

One of the results of the legal implementation of the rules of the Convention Medicrime in the Russian legislation was the adoption of the Federal law of the Russian Federation dated 31.12.2014 No. 532FZ On amendments to certain legislative acts of the Russian Federation on countering the trafficking of falsified, counterfeit, substandard and unregistered medicines, medicinal devices and falsified biologically active additives [3]. The law came into force on 23 January 2015. In accordance with the Federal Law of the Russian Federation Criminal Code is supplemented by three new articles: Article 235.1. Illegal manufacture of medicines and medicinal devices; article 238.1. Circulation of falsified, substandard and unregistered medicines, medicinal devices and trafficking in falsified biologically active additives; article 327.2. Forgery of documents on medicines or medicinal devices or the packaging of medicines or medicinal devices [4].

Although there are some deficiencies in the wording of these penal regulations, we believe their introduction in the Criminal Code is a serious step forward by the state to neutralize the trafficking of falsified and substandard medicinal products, and consequently to ensure the safety of the nation's health and economic security of the country. The inclusion of these special articles in the Criminal Code will allow to analyze statistical information on their practical application by the authorities, to investigate crimes, to fully implement the monitoring, prediction and prevention of these socially dangerous acts. It will contribute to the development and implementation of effective management decisions on the identification and investigation of crimes of this type.

In recent years, in the framework of the joint preventive measures to combat the circulation of 
falsified and substandard medicinal products there has been some constructive interaction between law enforcement and regulatory authorities, primarily by the bodies of internal Affairs and units of the Federal Service on Surveillance in Healthcare of Russian Federation. During 2010-2013 researches in the field of Economics, International and Criminal Law, Criminology, Criminalistics, Operatively-search activity, devoted to the development of measures to neutralize trafficking of falsified and substandard medicinal products, were developed as reserved dissertations. The legislation in the sphere of protection of public health and the turnover of medicines was updated.

Thus, trafficking of falsified and substandard medicinal products in the Russian Federation at present is not an appeal and not a theory, but there is a real activity of specialists in the field of law and pharmacy, with a certain legal framework, scientific and methodological support.

However, this problem is not yet solved. The Indicator of withdrawn from circulation of falsified and substandard drugs remains high. In Russia by the end of 2014, 1109 batches of substandard, falsified and counterfeit medicines were detected and withdrawn from circulation. The volume of state quality control of medicines coming into circulation accounted for 16,3\% [5]. A serious danger is the increased level of falsification of pharmaceutical substances, $80 \%$ of which is imported to the Russian Federation on indirect contracts from China and India without proper control at customs posts.

The study of criminal cases and statistics about the trafficking of falsified and substandard medicinal products in the Russian Federation leads to the conclusion that this crime is of a latent character. Every year about 50 crimes are detected, for only 30-35 of them criminal cases are initiated, and only 15-20 of the investigated criminal cases are submitted to court. This indicates serious problems in proving the guilt of the perpetrators of these crimes and bringing them to justice. The fight against this crime requires long and reliable operational development of criminal groups, qualified investigation and trial. The special knowledge in the field of circulation of medicinal products is required at all stages, however, relevant educational programs to date have not been developed [6].

Trafficking of dangerous medicines over the Internet and the media remains widespread in the Russian Federation. Biologically active additives are sold uncontrollably outside of pharmacies. The scale and danger of these crimes is erroneously determined on the basis of market value of the seized medicines, and not on the basis of their type of action and dosage, the presence of direct threat of harm to life and health due to the content of harmful substances. Obviously, a spread of just a few packages of falsified or substandard medicines, which contain dangerous ingredients, or contain no active substances, can have irreversible impact for health of people.

CONCLUSIONS: Detection, suppression, investigation and prevention of trafficking of falsified and substandard medicinal products should be systematic and not periodic in nature. It is necessary to organize training, close cooperation and continuous exchange of experience between specialists in the field of criminal law and pharmacy in the fight against this criminal phenomenon.

Law enforcement and regulatory agencies need to adopt joint normative legal acts, regulating their functions and powers in joint fight against trafficking of falsified and substandard medicinal products.

The use of an official position in the crimes related to trafficking of counterfeit and substandard medicinal products should be considered as an aggravating circumstance when considering qualification of those socially dangerous acts.

It is necessary to develop a set of measures to prosecute Internet service providers, hosting and serving web sites, through which they operate the illicit trade of medicinal products on the Internet.

We should develop a mechanism of accountability of media for advertising and distribution of obviously false information about medicinal products.

It is advisable to tighten control over the circulation of biologically active additives, prohibit their sale outside pharmacies. 
It is necessary to revise the legal framework and to tighten control over the conduct of clinical trials of medicines and the legality of their registration.

Keywords: Trafficking, falsified, substandard, medicinal products, enforcement, legal framework, international law, convention

\section{Conflict of interest statement: None.}

\section{References}

[1] Employees of Interpol Russian Interior Ministry took part in an international police operation Pangea, [Internet] (accessed 2015 June 25) Available from: https://mvd.ru/news/item/3587248/

[2] Council of Europe Convention on the counterfeiting of medicinal products and similar crimes involving threats to public health. - Moscow, 28.X.2011.

[3] On Amendments to Certain Legislative Acts of the Russian Federation with regard to countering trafficking in counterfeit, counterfeit, substandard and unregistered medicines, medicinal products and counterfeit dietary supplements: Federal Law of the Russian Federation dated 31.12.2014 No. 532-FZ. Rossiyskaya Gazeta. January 12, 2015. No. 6572.

[4] The Criminal Code of the Russian Federation of 13.06.1996 No. 63-FZ, taking into account changes on, 2015 July 13.

[5] M.A. Murashko. The work Roszdravnadzor and its territorial bodies in 2014 (based on the final board) Vestnik Roszdravnadzor No. 2 (2015), 8-9.

[6] N.F. Faizrakhmanov, the investigation into the trafficking of falsified and substandard medicines, biologically active additives, Moscow (2013), 4. 